\title{
JUSTICIA EN TROYANAS DE EURÍPIDES
}

\section{Paula Cristina Mira Bohórquez}

[ Universidad de Antioquia, Colombia ]

[ paula.mira@udea.edu.co ]

ORCID: 0000-0003-4999-2357
Resumen: En el artículo realizaré un estudio de algunos pasajes de Troyanas de Eurípides, en busca de posibles sentidos de justicia en el texto. En primer lugar, analizaré el pacto realizado entre Poseidón y Atenea en la primera parte del prólogo (1-97); a continuación, me concentraré en la paradójica intervención de Casandra, antes de ser embarcada como esclava de Agamenón (308-461); para terminar, resaltaré algunos puntos del agón entre Hécuba y Helena, que tiene como juez a Menelao (860-1059). Considero que en estos pasajes hay alguna alusión a débiles concepciones de justicia, aunque llegaré a conclusiones pesimistas al respecto.

Palabras clave: justicia; Troyanas; Hécuba; venganza; Helena

\section{Justice in Euripides' The Trojan Women}

Abstract: In this article, I will study some passages of Euripides' The Trojan Women in search of possible meanings of justice in the text. First, I will analyze the pact made between Poseidon and Athena in the first part of the prologue (1-97); then, I will concentrate on the paradoxical intervention of Cassandra, before being embarked as Agamemnon's slave (308-461); finally, I will highlight some points of the agón between Hecuba and Helen, which has Menelaus as judge (860-1059). I consider that in these passages there is some allusion to weak conceptions of justice, although I will come to pessimistic conclusions in this regard.

Keywords: Justice; Trojans; Hecuba; revenge; Helen

\section{Introducción}

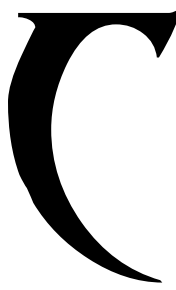

uenta Tucídides que, en la guerra del Peloponeso, los peloponesios asediaron largamente la ciudad de Platea, aliada de Atenas, de manera que esta, debilitada y casi sin víveres, terminó aceptando la propuesta de los lacedemonios de entregar la ciudad voluntariamente y permitir que estos fueran sus jueces, con la promesa de castigar sólo a los culpables de la alianza con Atenas. Se realizó el juicio, en el que los tebanos participaron en contra de los plateos: los jueces preguntaron a los hombres si habían prestado servicio a los lacedemonios o a sus aliados durante la guerra, cuando decían "no", los mataban. Así, los lacedemonios mataron a doscientos plateos y veinticinco atenienses que habían sido atrapados por el asedio, por su parte, las muje- 
res pasaron a la condición de esclavas. La ciudad fue entregada durante un tiempo a megarenses, pero luego fue destruida y con los materiales fue construido un santuario de Hera. Así, narra Tucídides, terminó entonces la cuestión de Platea, después de haber sido aliada de Atenas durante 92 años (Historia de la Guerra del Peloponeso 3.52-68). La historia de Platea no fue una historia poco común ni antes ni durante la guerra del Peloponeso, la práctica de las expediciones que terminaban con la muerte de los hombres y la esclavitud de mujeres y niños era tan extendida que, años después de Tucídides, Aristóteles en su Política (1255a3-1255b15) diferencia entre "esclavitud natural" y "esclavitud legal" y nos introduce en la discusión sostenida sobre la última. El esclavo "por ley" lo es por el acuerdo según el cual "aquello que se conquista en guerra pertenece a los conquistadores" (1255a6-7). Muchos, nos indica Aristóteles, rechazan esta "justicia", pues les parece temible que quien ha sido objeto de violencia sea sometido por aquel que tiene más poder y puede ejercer la violencia ${ }^{1}$.

Eurípides escribió Troyanas durante la misma guerra que narra $\mathrm{Tu}$ cídides, en épocas en que, a pesar de una tregua, la guerra se había hecho parte de la cotidianidad ateniense ${ }^{2}$.

1 Aristóteles, en efecto, pone en cuestión la "justicia" de la "esclavitud por ley", llegando a la lamentable conclusión de que aquella que se justifica es la "natural" (Política 1255a3-1255b15; 1255b16-40).

2 A Claudio Eliano (Historias curiosas 2.8) le debemos la clara datación de esta obra
Su obra tiene bastante en común con la narración sobre el destino de Platea y la discusión planteada por Aristóteles sobre la esclavitud. La obra muestra el sufrimiento de las mujeres

y la información de las demás obras de la tetralogía. La obra fue representada en el 415 a.C. (el año de la nonagésima primera Olimpiada), junto con dos tragedias, también del ciclo troyano, Alejandro y Palamedes, así como el drama satírico Sísifo (la tetralogía ganó sólo el segundo puesto, el primero lo obtuvo un tal Jenocles, del que no se tiene más noticia). No es posible saber si el segundo puesto que obtuvo el autor en las dionisíacas se debió a un afán crítico de los espectadores contra el decidido carácter antibélico de la obra; es conocida ya la propuesta de Murray (1962: 134-135) de relacionar esta obra con la captura de Melos por parte de los atenienses, como una especie de antecedente inspirador de la obra. La captura de Melos tuvo lugar en el 416 a.C., la ciudad fue destruida por los atenienses, sus hombres asesinados y sus mujeres y niños esclavizados. Este ataque no tuvo ningún efecto importante en el desarrollo de la guerra, la ciudad fue destruida, al parecer, sin fin alguno. Tucídides, sin embargo, le dedica muchos capítulos de su obra (Historia de la Guerra del Peloponeso 5.84-116), concentrándose, como resalta MURRAY (1962: 134-135), más en cuestiones morales de esta invasión que en problemas militares. Ha sido ya muy discutida la presunta influencia del episodio de Melos en Eurípides a la hora de escribir la obra; Melos fue atacada en el 416 a.C. y la obra se presentó en la primavera del 415 a.C., la proximidad de ambas fechas hace improbable la relación entre Melos y la escritura de Troyanas. Aun así, como indica Croally (1994), el acento podría estar, no en la escritura, sino en la representación de la obra; para cuando se representó el pueblo ateniense sabía ya lo sucedido en Melos, de manera que la obra podía servir para hacerse un juicio sobre lo sucedido. Para una visión crítica a la postura de CroAlly, véase la introducción a la obra de Kovacs (2018). 
troyanas en el tiempo que pasa entre la caída de Troya y la partida de ellas, ya como esclavas, en las naves de los griegos. Su protagonista indiscutible es Hécuba, que ocupa con su dolor toda la escena. La viuda de Príamo lo ha perdido todo ya al inicio de la obra, y, sin embargo, en el transcurso de la acción trágica le sobrevienen todavía más males y le llegan noticias que ahondan más su dolor. Casandra y Andrómaca son también esclavas ya, a la espera de la partida. Helena, aunque en situación similar a las demás, tiene posibilidades de un mejor desenlace, debido a que será entregada a Menelao, su antiguo esposo ${ }^{3}$. Así,

3 La obra sólo tiene dos personajes masculinos en escena: Taltibio y Menelao. Aparece también Astianacte, hijo de Héctor y Andrómaca, asesinado por los griegos, precisamente, para no permitir que crezca el último hombre de Troya, el hijo del más excelente padre (718). De su presencia nos enteramos porque Hécuba nos informa que llega al campamento al lado de su madre (568-571); de su dolor por el angustioso discurso de despedida de esta (735-774), y de su muerte porque al final de la obra es entregado a su abuela Hécuba para recibir sepultura (1119). Taltibio es, por un lado, el típico personaje del heraldo en la tragedia, que tiene la función de transmitir noticias y generar así un cambio en el desarrollo de la acción. Pero, por otro lado, es una versión distinta del heraldo, pues, no sólo tiene nombre, sino que además desarrolla una relación con las troyanas marcada por la compasión e incluso por la vergüenza por aquellos mensajes que debe enviar de parte de los griegos a estas mujeres $(712,781$ 784). Como lo indica Gilmartin (1970: 213), el personaje no sólo tiene una función dramática, sino que representa lo poco que queda de orden y civilización entre el desastre, el dolor y la ruina. El otro personaje masculino es Menelao, que cumple la
Troyanas es una obra que pone en tablas el dolor femenino, narrado por aquellas mujeres que, como tantas mujeres griegas y 'bárbaras', sobrevivieron a los hombres de sus ciudades en las guerras, para ser esclavizadas por otros hombres. Troya, como Platea, ha dejado de existir; para cuando empieza la acción trágica es, según Poseidón, "humo y cenizas" (8-9) para cuando esta termina, Taltibio nos informa que los capitanes van a incendiar la ciudad, para acabar definitivamente con ella (1260-1264). El final de la obra está además determinado por la ironía trágica, reflejada en que las mujeres lloran por el anonimato en que caerá Troya (1319), mientras el espectador sabe que no hay ciudad de mayor fama.

No hay en esta obra una presentación de héroe trágico en algún sentido común del término. Algunos puntos contribuyen a ello: 1) las mujeres tienen pocas posibilidad de agencia, dado que son vencidas $y$, precisamente, parte del desarrollo de la obra se trata del proceso de esclavizarlas y entregarlas a sus "amos"; 2) han perdido el dominio de sus vidas, de forma tal que la presencia de Taltibio, el heraldo de los griegos, es esencial en la obra, porque sólo a través de él pueden saber qué será de ellas; 3 ) no hay para ellas nada que decidir, ni hay

función de juez en el ágon entre Hécuba y Helena (860-1059), como en muchas otras versiones de la mitología es un personaje débil, que adivinamos manipulable.

4 La citación de los pasajes sigue las ediciones de Paley (1857-2010) y de Kovacs (2018). La traducción es propia. 
en la acción trágica posibilidad de cambio alguno en el desarrollo de la acción: Troya está destruida, la guerra ha acabado, la acción que está por venir está fuera del espacio y el tiempo de estas acciones. En este sentido, las mujeres hacen parte de un entramado de acciones que las trasciende $\mathrm{y}$, sólo en algunas ocasiones, como en el caso de Helena y su intento de convencer a Menelao de su inocencia para salvarse (860-1059), pueden tomar algún control de las circunstancias. Los héroes griegos de las aventuras troyanas han muerto en su mayoría y de aquellos que siguen vivos sólo tenemos noticias por medio de Taltibio; la presencia de estos sólo llega a nosotros por la visión que las mujeres tienen de su participación en su trágico destino. Es el caso de Agamenón, que se llevará a Casandra (249); y de Odiseo que, no sólo se llevará a Hécuba, sino que además aparece como un ser terrible, que ha ordenado la muerte del hijo de Andrómaca $(277,716)$; así también de Ajax "el menor" (hijo de Oileo de Lócrida) que ha violado a Casandra en el templo de Atenea (71). El muerto Aquiles también siguen teniendo influencia en la acción, pues sobre su tumba ha sido sacrificada Políxena (264) (aunque esta acción no aparece en la acción dramática). Por último, Menelao, único héroe presente en la acción, también llega a tomar en sus manos el destino de Helena. Así, entonces, esta es una acción trágica en la cual los hombres están ausentes, pero, al mismo tiempo, determinan el destino de las mujeres presentes.
Dado lo expuesto hasta ahora, pareciera que la obra presenta la ausencia total de justicia para estas vencidas en la guerra; así como que hay un orden de cosas establecido en la posguerra, que no incluye justicia, venganza, reivindicación o protección alguna para estas. Las guerras suelen terminar con pactos o tratados que, en la medida de lo posible, garanticen algún tipo de justicia para las partes. Atenas misma negoció varios durante la guerra del Peloponeso; en el 421 a.C. terminó la primera parte de la guerra con la llamada "paz" de Nicias, un acuerdo que, aunque fue muy irrespetado, dio alguna tranquilidad a dos bandos agotados. También en el 404 a.C., tras su rendición, Atenas vivió los beneficios de un trato justo, cuando los Espartanos se negaron a destruirla. Estos pactos se dieron entre hombres y garantizaban un mejor final para los Estados. El caso que muestra Troyanas nos lleva a plantear la pregunta sobre si, no habiendo dos bandos de hombres guerreros, dos Estados comprometidos, sino mujeres vencidas, es posible pensar un final de guerra que pueda garantizar un mínimo de justicia. ¿Hay justicia para las no guerreras, para las mujeres solas, para las esclavas? o ¿nos sitúa Eurípides en la perspectiva de que la justicia que permite transitar de tiempos de guerra a tiempos de paz sólo se pacta entre hombres y sólo a estos beneficia? En las siguientes páginas analizaré los posibles sentidos de justicia que se manifiestan en la obra y su influencia en las vidas de estas mujeres, al menos en los momen- 
tos que constituyen la acción trágica. Habrá que decir desde este momento que estos análisis, aunque presentan algunos sentidos de justicia, no podrán cambiar la idea fundamental de que estas mujeres son botín de guerra, que quedan al arbitrio sin control de quienes las esclavizan. Las troyanas están sometidas a la "justicia" propia de la guerra, que ya había reseñado con Aristóteles, según la cual: "aquello que se conquista en guerra pertenece a los conquistadores" (Política 1255a6-7). Bajo esta concepción, los conquistados en guerra pierden su condición de humanos libres y pasan a ser propiedad, con la consecuencia obvia de que la justicia sólo protege a los humanos libres, porque a la propiedad ha de protegerla su dueño, el cual, sin embargo, no está sometido a ningún escarnio ni crítica por aquello que haga con lo que le pertenece. También según esta concepción de justicia, no hay razón para que quien vence en la guerra no tome el botín, que, sin cuestionamientos, le pertenece; así, no tendría sentido esperar para estas mujeres un futuro distinto, porque sus vidas han pasado a ser regidas por la justicia que protege al conquistador.

En primer lugar, analizaré el pacto realizado entre Poseidón y Atenea en la primera parte del prólogo (1-97); a continuación, me concentraré en la paradójica intervención de Casandra, antes de ser embarcada como esclava de Agamenón (308-461); para terminar, resaltaré algunos puntos del agón entre Hécuba y Helena, que tiene como juez a Menelao (860-1059).
Considero que en estos pasajes hay alguna alusión a débiles concepciones de justicia, aunque concluiré que, para la tragedia de las troyanas no presenta Eurípides consuelo alguno.

\section{Poseidón, Atenea y el pacto}

C 1 prólogo de esta obra es típico de Eurípides ${ }^{5}$ empieza con un monólogo hablado, en este caso el de Poseidón (1-47); seguido de un diálogo, en este caso entre Poseidón y Atenea (47-97). Al final tiene lugar una monodia lírica de los personajes principales, la de la obra es de Hécuba (99-152). La primera parte del prólogo nos da todos los detalles esenciales para ubicarnos en la acción trágica, poniéndonos en contexto sobre los acontecimientos inmediatamente anteriores. Como en otras obras, el monólogo de apertura lo hace un dios: Poseidón.

El monólogo de Poseidón nos brinda toda la información necesaria para ubicarnos en la escena. Este primer monólogo se podría dividir en dos partes. La primera nos brinda información sobre lo sucedido poco antes de la acción trágica, nos ubica en la caída de Troya. Así, esta primera parte podemos a la vez subdividirla de la siguiente manera. 1) El dios nos cuenta que ha abandonado la profundidad del mar. 2) Canta su amor por los frigios. 3) Ubica al espectador en

5 Prólogo, según el modelo aristotélico, es todo lo que va antes de la párodos (Poética 1452b19-20). La párodos, dice Aristóteles, es la primera aparición del coro (Poética 1452b22-23). 
el estado actual de Troya: "que humea, destruida y devastada por las lanzas argivas" (8-9). 4) Le cuenta al espectador cómo ha sido destruida Troya, con el "caballo de madera" (14), y habla sobre la profanación de los templos, pues Príamo ha caído en el de Zeus (16-17). 5) Poseidón ubica a los frigios en la escena e informa que se disponen a volver a casa (18-22): vencido él también en esta guerra por Hera y Atenea, abandonará Troya. En Troya ya no hay nada que salvar, ni nadie que pueda rendir culto. En esta parte, así como en el diálogo con Atenea, Eurípides parece privilegiar la visión de dioses interesados y ofendidos en su ego (23-35). 6) La parte final de esta primera mitad del prólogo es la que nos ubica propiamente en el páthos central de la obra, en el dolor de las mujeres troyanas; de ellas se dicen que: "el eco de sus lamentos resuena en el Escamandro" (28-29). Poseidón nos ubica en una escena en la playa, bajo las tiendas de los ejércitos griegos. En ellas están las mujeres que "aún no han sido sorteadas", entre quienes está también Helena. Presta Poseidón especial atención al dolor de Hécuba, de nuevo Eurípides concentra la atención en el páthos, en las lágrimas y las desgracias, esta vez el de su protagonista (36-47). Este monólogo entonces ofrece una visión panorámica de la situación que enmarca la obra, para terminar en la situación concreta de su protagonista. Me concentraré en el análisis de un par de pasajes especialmente relevantes para el tema de este escrito, teniendo en cuenta, además, que estos pasajes constituyen buenos ejemplos de ironía trágica.

a) En 19-22 Poseidón nos informa que los helenos están cargando sus barcos con los trofeos de la guerra y esperan un viento favorable para volver a casa a ver esposas e hijos, después de diez años. El dios, en este caso, no posee la información que cualquier espectador conoce, a saber, que buena parte de los helenos no podrán llegar a sus tierras y que no habrá buen viento. Pero, además, resaltar la esperanza de los helenos contrastará fuertemente con las siguientes escenas, en las cuales Poseidón pactará, precisamente, no permitir el regreso de los helenos a su casa. Al contarle al espectador que Helena también está en escena, Poseidón nos dice que es "correctamente considerada prisionera" (35). Este apartado anticipa el foco que pondrá la obra en Helena como la culpable de las desgracias de Troya en general y de las mujeres troyanas en concreto $^{6}$. De hecho, como veremos más adelante, el único juicio que vemos en la obra es el hecho a Helena.

b) Hacia el final de su parte del monólogo (36-44), el dios eleva el patetismo de la obra, no sólo

6 Hall y Morwood (2000) interpretan este constante tono adverso contra Helena en la obra como un tono antiespartano, comprensible también por los tiempos de guerra que se viven cuando se presenta la obra. 
hablando de Hécuba postrada y gimiendo, sino además haciendo un recuento de los males que la aquejan. Pero, algunos son males de los que la misma Hécuba aún no está enterada: el sacrificio de Polixena o la entrega de Casandra a Agamenón. Es decir, al empezar la obra Hécuba es ya una mujer destruida y compadecida por el dios, ha perdido a sus hijos y a su marido, pero, aún no se ha enterado del destino de sus hijas. El dios lo anticipa aquí a los espectadores, que entran a escena con Hécuba teniendo información sobre sus desgracias que el personaje no posee. La fuerza de este elemento dramático es grande, pues el espectador, al ver llorar a Hécuba por sus desgracias al principio de la obra, tendrá en mente que aún no se ha enterado de sucesos que harán más profunda su herida. El apartado es también una confrontación del destino de los hombres con el de las mujeres en la guerra. Príamo y sus hijos han muerto, literalmente: "han desaparecido" (41), como Troya. Por su parte, las mujeres no mueren en la guerra, su destino es seguir sufriendo vivas; ellas no desaparecen con su ciudad, sino que la abandonan como esclavas.

c) En su despedida, Poseidón ya determina claramente un culpable de lo sucedido a Troya: culpa a Palas Atenea (con quien líneas adelante pactará). Desde la perspectiva del dios, las culpas están claras, pero, dada la culpable, no hay justicia posible para los troyanos. Debido a que él ha perdido en la disputa contra Palas, se dispone a partir.

La segunda parte del prólogo (4897) es la parte dialógica, en este caso entre Atenea y Poseidón. Este diálogo sellará el destino de los griegos, que serán condenados a expiar sus crímenes no volviendo a casa. Sin embargo, los crímenes por los que serán condenados poco tienen que ver con lo sucedido a las mujeres troyanas. Antes de analizar este pacto es importante anotar que Eurípides conserva hasta este punto la línea de Ilíada, con Atenea presentada como amiga y protectora de los griegos, mientras ha cambiado la línea con Poseidón, que, si bien en esta obra es amigo de los troyanos, en Ilíada es también un dios a favor de los griegos. No obstante, a partir de este punto Atenea cambia también de bando. Estos cambios frente a Ilíada son favorables dramáticamente: Eurípides puede mostrar así en el diálogo la reconciliación de dos dioses de bandos contrarios y, además, elige al dios perfecto para este, pues sólo Poseidón puede llevar a cabo los designios de Atenea. Miremos entonces de qué se trata este pacto.

a) Atenea propone a Poseidón (su pariente) cesar las hostilidades, le indica que tienen intereses en común y le dice que ha ido a Troya para que se unan en una causa (48-58). Poseidón pregunta si el 
cambio de Atenea se debe a que ahora se compadece de los troyanos (59-60); la respuesta llegará pronto, y no tendrá nada que ver con la compasión. Ninguno de los dos dioses muestra compasión por el destino de los troyanos (ya vimos cómo Poseidón abandona Troya porque ya no habrá culto para él). Poseidón, al menos, conoce y resalta el destino de las troyanas y el dolor de Hécuba. Atenea, por su parte, ni las menciona, es totalmente indiferente al dolor dejado en la ciudad que, como se lo resalta Poseidón, ella misma ayudó a destruir (72).

b) Ante la pregunta de Poseidón sobre a quién apoya (63-64), Atenea confiesa su cambio de bando, usando una expresión bastante confusa: "quiero que los troyanos se alegren" (65). No es claro por qué habrían de alegrarse los troyanos por sus futuras acciones: por un lado, todos los hombres han muerto ya, de manera que nada de lo que suceda a los ejércitos griegos los puede afectar en modo alguno; por el otro, las únicas que quedan son las mujeres, para las que en la venganza planeada por Atenea no se retribuye nada del daño sufrido. Está claro entonces que es una expresión que refleja una actitud que, en realidad, no tiene nada que ver con los troyanos, sino que se enfoca en los griegos. El problema de Atenea no está en los crímenes cometidos por los griegos contra los troyanos, sino en las profanaciones cometidas contra ella. Esto se evidencia claramente cuando Atenea responde a Poseidón: “ ¿No sabes que hemos sido atrozmente insultados, yo y mis templos?" (69). Así también, al terminar de explicar en qué consistirá la ayuda de Poseidón en el castigo a los griegos, Atenea sentencia: "Para que de ahora en adelante los aqueos aprendan a venerar mis templos y a respetar a los dioses" (85-86). Así entonces, la preocupación de la diosa, única capaz de brindar justicia o "alegrar" a las troyanas, no es brindar justicia a los troyanos, menos a las troyanas. Sin duda la profanación de los templos está estrechamente ligada con lo sucedido a troyanos y troyanas: Príamo ha sido asesinado en el templo de Zeus, Casandra ha sido violada en el templo a la misma diosa (sobre esto último llama la atención Poseidón, no Atenea misma (70)); pero el centro de la ira de Atenea está en sus templos, no en quienes sufrieron en ellos.

c) Ante el recuerdo de Poseidón de que Casandra fue violada por Ajax en el templo de Atenea (70), el contrapunto de la diosa resalta de nuevo varios aspectos de su ira: "Y nada le han hecho, ni dicho" (71). Esto es, los aqueos no han tomado ninguna acción para castigar la profanación del templo (el punto de la violación de Casandra es aquí sólo secundario). La ira 
está entonces concentrada en que los aqueos: 1) han profanado sus templos y 2) no han castigado a quienes lo han hecho. De ahí entonces que sean más amargas para la diosa las palabras, ya mencionadas, pronunciadas por Poseidón, recordándole que ella misma les ayudó a destruir Troya (72).

Estos cortos pasajes emulan algunos aspectos de un juicio: se ponen en evidencia los crímenes cometidos, se evidencia el nulo interés de los enjuiciados en castigar a los criminales entre ellos, finalmente, se llega a la condena. La condena es el pacto mismo entre ambos dioses participantes en el prólogo y es aquella que la tradición le hereda a Eurípides; en palabras de Atenea: "quiero arruinar su regreso a casa" (75). Para llevar a cabo este castigo, informa Atenea que contará con la ayuda de Zeus (78-80). El pacto con Poseidón se debe a que este, como dios del mar, ha de acompañar los rayos que envíe Zeus con un gran oleaje, de manera que se llene: "de cadáveres la cóncava bahía de Eubea" (84). Atenea quiere entonces el castigo, como lo indiqué antes, para que los griegos aprendan a respetar a los templos y a los dioses. Es de destacar que, de hecho, dentro de toda esta trama, este es el único castigo que se infringirá a los griegos, la única forma clara de justicia que se llevará a cabo, en este caso justicia cuasi penal, bajo la forma de castigo por los crímenes cometidos. Pero, esta es una forma de justicia con algunas características especiales; precisamente, la ironía de que en este prólogo todo sea dicho en presencia de $\mathrm{Hécuba}^{7}$, pero, sin que ella escuche ni sea consciente de lo que se dice, fortalece el aspecto trágico de una justicia de la cual las troyanas, protagonistas de la obra, no tendrán noticia. El hecho de que los griegos no podrán realizar su viaje a casa es algo que quedará entre el espectador y los dioses; el accionar trágico de los personajes en la obra operará sin esta información del prólogo. Este prólogo constituye una acción que se cierra en su línea final: no tiene ninguna continuidad en la obra, no tiene influencia sobre las acciones de esta, no va entonces a constituir ningún tipo de justicia para las troyanas mismas.

\section{Casandra y el discurso paradójico}

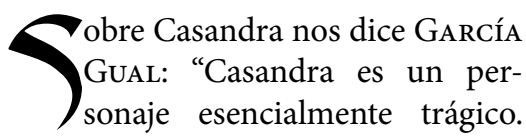
$\mathrm{Y}$ es en la tragedia, y no en Homero, donde se nos muestra en toda su peculiar grandeza patética" (2016: 180). Según las reconstrucciones de

7 Al respecto nos dice Kovacs (2018): "Que Hécuba esté presente durante el diálogo de las dos divinidades sin ser consciente de su presencia contribuye a una disonancia irónica. Los dos dioses discuten la dimensión divina de lo que le ha ocurrido a Troya y lo que les ocurrirá a los griegos. Hécuba, por el contrario, como se mostrará a lo largo de la obra, tiene opiniones (plurales e incoherentes entre sí) sobre de los dioses y su papel en el mundo, que se contradicen por este diálogo inicial de apertura, y por otras cosas, en esta obra y en Alejandro" (121). Traducción propia. 
la tragedia Alejandro, perteneciente, como se indicó, a esta trilogía (MURRAY 1962; SHAPIRO y BURIAN 2009), Casandra cumple ya en esta primera tragedia de la trilogía su papel trágico por excelencia. Allí, es ella la única que sabe que la suerte de Alejandro, al no ser asesinado por Hécuba, y la alegría de Hécuba, al no haber asesinado a su hijo, se traducirán en el dolor y la tragedia de Troya. Se trata de un ejemplo de lo que Murray (1962: 134) llama 'paracharaxis trágica', dado que en esta obra se pone en evidencia que las cosas que son llamadas buenas deberían ser llamadas malas y viceversa. Así entonces, se supone que en Alejandro Casandra es el único personaje que sabe que el mejor desenlace para la ciudad hubiese sido la muerte del mismo Alejandro; mientras el espectador está, sin duda, consciente de eso. En Troyanas, el personaje recita dos largas rhésis (308-461) en las que, paradójicamente, también presenta las situaciones de la forma en como sólo ella las puede entender. Se muestra una presunta alegría en el dolor, un triunfo en la gran derrota. Líneas más adelante tomaré algunos aspectos de estas rhésis para mostrar el sentido de justicia que trae Casandra a la obra.

Antes de eso, es necesario llamar la atención sobre la dramática introducción a la primera rhésis (308-340). En esta, Casandra se comporta como mujer celebrando sus nupcias, con los rituales correspondientes. Invita a cantar, invita a celebrar con ella ${ }^{8}$.

8 Sobre esta rhésis escribe Palley (18572010): "La tensión salvaje que sigue es admirablemente adaptada al carácter de
La ironía y el drama son aquí protagonistas y esto desde varias perspectivas. Por una parte, celebra las bodas quien va a ser entregada como esclava. Pero, en Casandra se trata de una alegría irónica, pues sabe, como sabe el espectador, que su "boda" significará la muerte de Agamenón y la caída de la casa atrida. Por otra parte, es su madre la principal espectadora de este espectáculo, y ella no conoce (no conocerá en toda la obra) el motivo de la loca alegría de su hija. Lo que logra aquí Eurípides es entonces ahondar en el páthos, profundizar el dolor de Hécuba, sumando otro dolor a su amplia lista. No sólo su hija será entregada a su boda "a punta de lanza, obligada por las armas argivas" (346-347); sino que, además, ha perdido la esperanza de que su destino la devolviera de su locura (349-350). La escena genera tensión entre madre e hija, así como entre los personajes y el espectador.

La primera rhésis (308-340) puede dividirse en varias partes: 1) predice la ruina que, por su boda, caerá a la casa de Agamenón (353-364); 2) afirma que el destino de los aqueos en la guerra ha sido el peor (365-385); 3 ) afirma que el destino de los troyanos en la guerra ha sido el mejor (385-

una frenética doncella, que pretende irónicamente que está haciendo un espléndido matrimonio mientras está a punto de convertirse en la concubina de un rey soldado. Invoca a Himeneo, mientras blande la antorcha nupcial; llama a su madre, incluso en medio de su luto, para que sea testigo de su alegría, y a las doncellas troyanas para que canten y bailen con ella" (465, nota 308 ). Traducción propia. 
405). La segunda rhésis (424-461) se puede dividir de la siguiente forma: 1) predice el tormentoso viaje a casa de Odiseo, además de la muerte de su madre y de su propia muerte (424$450)$; 2) reitera la ruina de los atridas y se despide (451-461). De estas, la primera (308-340) es la que resulta más interesante para el presente análisis, por cuanto consolida la visión vengativa de Casandra, y su intento de cambiar el sentido de la derrota. Como lo que indica Murray sobre este personaje (1962: 150): “En lo más sombrío y profundo de la derrota de Troya ve ella el principio de la venganza triunfante de ésta”. Venganza que, desde la perspectiva del personaje, y sólo de este personaje, significará la justicia para los derrotados. Procedo entonces a resaltar algunos aspectos de esta rhésis.

a) Inicialmente (353-364), cuando Casandra empieza a hablar con su madre y le dice que vengará a su padre y hermanos, se genera de nuevo ironía trágica; esta se da por un pacto entre el espectador y Casandra, del cual los demás en escena no pueden hacer parte. El espectador antiguo conocía bien el destino de Casandra al llegar a la casa de Agamenón; nosotros lo conocemos porque Esquilo nos lo ha contado brillantemente en su Agamenón. Casandra y Agamenón morirán a manos de Clitemnestra, desatándose así una saga de venganza y muerte. La alegría de Casandra por sus bodas es una alegría por la venganza implicada en estas. Esta visión de venganza se ve consolidada, en primer lugar, en la comparación de su boda con la de Helena: así como la boda de Helena significó la desaparición de Troya, así, predice Casandra, su boda significará la desaparición de la casa atrida. En el mismo sentido afirma GARCí́a Gual (2016: 181): "Hay en la figura de Casandra, la cautiva de Agamenón, un extraño contraste con Helena, como señala Elisabeth Frenzel. El rapto de la reina de Esparta será falta para Troya; el de la hija de Príamo será fatal para Agamenón" En segundo lugar, Casandra se atribuye a sí misma el crimen que, sabemos, no comete ella (matar a Agamenón), enfatizando, además, que vengará así a su padre y hermanos (356-360). Lejos de verse como sacrificada, Casandra se percibe así misma como justiciera. Pero la conexión irónica y trágica con el espectador se establece, precisamente, por el hecho de que este sabe que Casandra sí será sacrificada, en un conflicto que nada tiene que ver con ella, y que, de hecho, nada tiene que ver con los troyanos. De la misma forma, la total ignorancia por parte de su madre de la historia por venir no le dejará consuelo alguno; Hécuba no logrará comprender el sentido de justicia para con su esposo y sus hijos. Algunos aspectos de esta "justicia" vengativa son similares a los vistos en el caso del pacto entre Poseidón y Atenea. Primero, aquella ven- 
ganza de la que habla Casandra se consolida en acciones que sobrepasan el tiempo de la obra; segundo, la venganza prometida sería para Príamo y sus hijos muertos, no para las mujeres esclavizadas. Llama la atención cómo Casandra no se incluye, en este pasaje, a sí misma en la promesa de venganza: no habla de vengarse por aquello que le han hecho. Irónico es también el hecho de que su violación sea la única ofensa contra las troyanas que será vengada, como vimos en la primera parte, aunque, en ese caso, la justicia esté dirigida a la profanación del templo.

Así, ni Príamo ni sus hijos experimentarán directamente justicia alguna, ni, en todo caso, las mujeres troyanas. Para su madre, todo este discurso es una desgracia más de uno de sus hijos; de una hija que, no sólo perderá también trágicamente, sino que, además, desde su óptica, ha perdido la razón.

b) Precisamente, la locura de Casandra establece el punto de partida de su discurso paradójico, a saber, parafraseando al Gorgias de Platón, el de la demostración de que es mejor ser derrotado en la propia casa que vencedor en casa ajena, o, como lo indica Murray (1962: 150), la demostración de que: "los justos vencidos son más felices que los injustos vencedores". Para asumir esta demostración, Casandra, primero, reconoce estar poseída por la locura báquica, pero, en segundo lugar, afirma estar libre de esta locura al momento de dar su discurso (366-367). Esta es una afirmación que debe poner tanto al espectador como a los demás personajes en escena en alerta, para prestar especial atención a lo que viene y tomarlo en serio; pero que, dada la compleja tesis que el discurso defiende, no encuentra eco en los demás personajes y resulta difícil de aceptar para el espectador. Eurípides sabe dejar sola a Casandra en su tesis de que los justos, derrotados y muertos son más felices que los injustos y vencedores, aunque muchos de ellos estén también muertos. En realidad, Casandra procede de manera ordenada, dando primero argumentos a favor de la infelicidad de los vencedores griegos (365-385), para pasar a probar la felicidad de los vencidos troyanos (386-405). Los argumentos de Casandra sobre la felicidad del vencido se pueden resumir de la siguiente manera. 1) Los griegos han iniciado semejante guerra por causa de una mujer (368-369). En este argumento se une a la constante animadversión de los personajes de la obra frente a Helena, y, además, este presupone una antesala importante, porque Helena sigue en escena y puede responder por sus actos. 2) Agamenón ha perdido lo que más quería por culpa de su hermano y de una mujer que: "vino voluntariamente y no raptada" (370-373). La primera 
parte de la afirmación es una clara alusión a Ifigenia, sacrificada por Agamenón para tener buen viento y poder llegar a Troya, aunque Casandra no tenía por qué saber esta historia. La segunda contrasta con la defensa que Helena intenta hacer de sí misma líneas más adelante. 3) Los griegos murieron lejos de sus casas y sus cuerpos han quedado en la tierra troyana, mientras en sus casas las viudas y los huérfanos no tienen tumbas sobre las cuales llorar (373-385). Si bien Casandra resalta en su demostración algunos de los puntos más trágicos de toda guerra, no todo en su argumentación habla a su favor. Sin duda, la apuesta de perder a Ifigenia en sacrificio, en el caso de Agamenón, así como de perder miles de vidas, en el caso de todos los troyanos, con el único objetivo de recuperar a una sola mujer, es desproporcionada y representa una gran pérdida para los griegos. Pero, y aunque esto no compense la pérdida de vidas, lo paradójico es que los griegos, como trasfondo de esta escena, están saqueando Troya y están, como lo dijo Poseidón, cargando los barcos de oro (18-22). Más paradójico aún, los griegos se están cobrando el botín con las mismas mujeres que escuchan este discurso. El argumento de Casandra apunta a la tradición de tantas culturas de poder enterrar a sus muertos y resalta el drama de toda guerra, en la que muchos hombres se van y no vuelven, ni vivos ni muertos. Las palabras de Poseidón al principio de la obra, donde señala que los griegos esperan buen viento para poder llegar a casa (18-22), fortalecen esta visión presentada por Casandra de unos griegos cansados de la distancia, deseosos de emprender por fin el viaje de regreso. Lo que queda en entredicho es si estas palabras también fortalecen no sólo la idea de la felicidad del vencido, sino también la de que hay justicia para los troyanos en estos padecimientos de los griegos.

El siguiente apartado (386-405) recupera los anteriores argumentos, pero esta vez a favor de los troyanos. De estos se dice que tuvieron la gloria de morir en su tierra, enterrados por su familia. De Héctor se dice que adquirió fama con esta guerra; e, incluso, de $\mathrm{Pa}$ ris se dice que se casó con la hija de Zeus, lo que lo libró de un matrimonio oscuro. Esto último, en franca contradicción con el desprecio que Casandra ha mostrado líneas antes frente a Helena, pero también con el argumento de que los griegos han perdido miles de vidas sólo por ella. En este argumento, más arriba comentado, no se hace alusión al linaje de Helena, que bien podría ser también argumento para que los griegos la quisieran de vuelta. Y esto muestra que quizá esta parte de la argumentación es la más frágil, porque fama han alcanzado todos los héroes caídos en esta guerra, griegos $y$ troyanos, y el feliz matrimonio 
no ha sido tal. Una cosa es que los griegos hayan perdido mucho en esta guerra, otra, que hayan perdido más que los troyanos. Una cosa es entonces que el vencedor no sea feliz, otra que el vencido lo sea más que el vencedor.

Aun así, hemos de decir que no parece haber sarcasmo alguno en las palabras de Casandra y que ella está convencida de aquello que han ganado los troyanos en esta guerra. También, que Casandra habla en tono heroico, pues la fama lo era todo para los héroes (García Gual 2020: 30). Pero es precisamente en este punto en el que es claro que la justicia, así sea bajo esta perspectiva de quién tiene más gloria en la muerte, está reservada para los hombres. Incluso si su discurso tuviera un eco real en las mujeres que la escuchan, la posición de Casandra se basa en la justicia para el guerrero, que no hace referencia alguna al daño vivido por las mujeres en la guerra. Es posible que, de tener eco, las mujeres entendieran estos argumentos como el consuelo por estar del lado de los "más felices", aunque no de los vencedores; pero, esto no daría consuelo alguno para su situación de esclavitud. Quienes reciben justicia a través de la fama, si el argumento convence, son los hombres muertos, no las mujeres vivas.

El discurso paradójico de $\mathrm{Ca}$ sandra es un juicio de guerra en el cual no es realmente claro que gane el vencido. $\mathrm{Y}$, aun así, es un discurso hermoso, porque resalta que, en realidad, nadie gana una guerra; que en toda guerra hay dos bandos sufriendo y perdiendo y que detrás de todo combatiente hay familias (mujeres, niños, ancianos) que sufren en la guerra sin combatir y quedan siempre abandonados en el camino.

El final de esta rhésis resalta dos puntos. El primero es una corta reflexión aleccionadora (400-404), muy propia de Eurípides. Y el segundo es la promesa que Casandra hace a su madre de vengarse (404-405). En la reflexión Casandra afirma que es malo hacer la guerra, contradiciendo la idea de que la guerra es natural e inevitable. Pero, si se hace, afirma, hay que morir en ella dignamente. La promesa, por su parte, consiste en el retorno a lo dicho antes con respecto a su destino. Llama la atención que, de nuevo, Casandra se apropia de un acto que no es suyo (el asesinato de Agamenón), aunque esta vez es clara en mostrar que matará a sus enemigos a través de su boda, mostrándose así a sí misma como arma de venganza. Es importante, además, resaltar que esta sí es una promesa hecha en nombre de las mujeres, por cuanto dice a su madre que se vengará: "de los enemigos que más odio y de los tuyos" (404-405).

Dos reacciones genera la primera parte de la rhésis: la primera es del coro, en cuya voz Eurípides resalta, precisamente, el problema de este tipo de justicia, pues se trata de una promesa lejos del actual sufrimien- 
to de las mujeres. Así, el coro dice: "cuán alegremente te ríes de los males de tu casa y cantas lo que no se ha cumplido" (406-407). La segunda es la de Taltibio, que, indignado por el insulto contra los griegos, afirma que nunca tomaría como esposa a una mujer loca como ella (408-423). En ambos casos se ve que el discurso de Casandra no surte efecto: las troyanas (el coro) no comparten su idea de la felicidad de los vencidos, por el contrario, lo encuentran como una burla. Taltibio entiende el tono ofensivo del discurso para con los griegos, pero no se toma en serio la afirmación hecha por Casandra de que está hablando desde la cordura.

La reacción al final de ambos discursos nos lleva al mismo punto (466 ss.). Nadie entiende las palabras de Casandra, ninguna troyana se siente consolada por su promesa de venganza. El argumento en favor de la felicidad de los vencidos no cambia en nada el dolor del momento. Hécuba se derrumba ante la partida de su hija; no comparte su felicidad, no entiende su venganza, no reacciona ante la idea de que su marido y sus hijos muertos han tenido un mejor final que los muertos griegos. $\mathrm{Y}$ con este contraste, precisamente, marca Eurípides la soledad de Casandra, su carácter de "personaje esencialmente trágico". Trágico también porque morirá una muerte terrible que a nadie consolará, que no será buena para nadie. El sentido de justicia, entonces, en estas bellas palabras de Casandra, no sólo no se consolida en la obra misma y frente a lo sufrido por las mujeres, sino que no encuentra comprensión alguna por parte de ningún personaje. Las mujeres no mueren con fama, son anonimizadas por la esclavitud sexual. Desde la perspectiva femenina, $\tan$ bien retratada aquí por Eurípides, la fama del muerto no significa nada, porque la muerte de los hombres significa la soledad y la indefensión de las mujeres. Ya se lo dice Taltibio a Andrómaca cuando le anuncia que su hijo será asesinado: "No tienes ayuda en ningún lado, piénsalo, han desaparecido tu ciudad y tu marido" (724-725). Cuando los hombres mueren las mujeres no tienen a quien recurrir, quedan indefensas, de ahí que las palabras de Casandra no generen ningún impacto (de ningún tipo, porque en realidad nadie se toma en serio sus reflexiones).

\section{Justicia y el juicio a Helena}

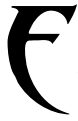
n 860 entra Menelao a escena. Lo hace, como es usual en la primera entrada de un personaje, con un monólogo (860-883) que presenta al personaje o, como en este caso, presenta su visión sobre los hechos acontecidos en la obra. La perspectiva de su monólogo nos muestra la necesidad de justicia del otro lado de la moneda, el de los griegos y la forma en cómo, del modo como lo presenta Menelao, de alguna forma se ha hecho justicia. Así, Menelao informa que no ha ido a Troya a recuperar a su esposa (contrario a lo planteado por Casandra), sino a buscar a quien él hospedó en su casa y luego la robó (864-868). Menelao, incluso, considera que en ese sentido 
se ha hecho justicia pues quien la ha robado ya ha muerto "por lanza helénica" (868). El único cabo suelto que queda entonces, desde esta perspectiva de justicia, es Helena misma, la mujer robada. Sobre esta, nos informa Menelao, ha habido ya una suerte de juicio entre los guerreros griegos ("aquellos que lucharon por causa de ella", 873-874), que han autorizado al otrora esposo, o a matarla, o a llevársela sin matarla a Argos (874-875). La decisión de Menelao, informa, ha sido la de matarla en tierras griegas, para compensar así a aquellos que han perdido la vida en Ilión (876-879). Como resalta Kovacs (2018: 267), no se supone que un personaje no sea sincero en un monólogo de este tipo. Por lo tanto, podemos partir del hecho de que Menelao sí ha entendido la guerra como una cruzada para vengar la injusticia cometida contra él y su casa, y que, una vez terminada esta tarea con los hombres, ha de proceder con la mayor culpable del asunto. También ve Menelao a Helena como la culpable de la guerra y, en este caso, como la culpable de las muertes griegas. Helena es entonces vista como la culpable por excelencia de todos los dolores y penas que hay de fondo en esta obra y es culpable para ambos bandos. Quizá sea por esto que Eurípides introduce a Menelao, así como al posterior agón (911-1059) entre Hécuba y Helena: precisamente para plantear un juicio final a la última culpable de las desagracias de las troyanas. Pero las consecuencias de este juicio no quedan del todo claras, así como tampoco entonces el resultado de este último intento de brindar justicia a estas mujeres. Es por esto que, para terminar este escrito, presentaré algunos aspectos de la escena en cuestión, relevantes para el tema. Terminaré con los confusos resultados del agón y la pregunta por si se concede la justicia pedida por Hécuba al iniciar este juicio o si es posible sostener la perspectiva de que este juicio es una más de las calamidades sufridas por esta mujer.

a) Es necesario, sin embargo, retomar la escena del monólogo de Menelao, y su posterior comunicación con Helena y Hécuba, para llamar la atención sobre varios puntos relevantes para el análisis. Primero, Helena, como todas las demás "prisioneras" (871-872), como las llama Menelao, no conoce su suerte y también debe preguntar qué han decidido los griegos sobre su vida (900). La suerte de Helena será distinta de la del resto de estas prisioneras, pues Menelao le informa que no ha habido claridad en el ejército sobre qué hacer con ella y que han decidido que sea entregada a él, que es el "ultrajado", para matarla (901-902). Entonces, aunque Helena no esté condenada a ser esclava, el agón significará para ella una lucha por la vida. Es entonces cuando Helena pide justicia para ella misma, pues pide hablar para probar que, si muere, será injustamente (903-904). La visión de ambas mujeres sobre su situación produce un contraste dramáticamente fuerte. Helena 
es el contrapeso de Hécuba en varios sentidos, quizá el principal de ellos es que la primera también considera que tiene razón, que es una víctima, que debe recibir justicia; pero también que Hécuba está en manos del bando contrario, mientras la maleabilidad de las lealtades de Helena no la atan a un solo destino. A diferencia de Hécuba, a quien sólo le queda sufrir su destino de esclava, Helena todavía tiene la posibilidad, no sólo de salvar su vida, sino de ser llevada a su antiguo hogar y de seguir su vida allí (como de hecho lo indican muchas tradiciones del mito). Sobre esto último Hécuba ya ha expresado de alguna forma su miedo, pues ha pedido a Menelao no mirar a Helena a los ojos, debido a su gran poder seductor (890-894). Eurípides, según mi lectura, pone aquí un elemento que siembra la duda acerca de las posibilidades de que Helena sea, en efecto, la única mujer en salir bien librada de esta tragedia.

Aun así, Menelao no cambia su opinión, pues estaba sinceramente convencido de terminar la venganza por los actos cometidos matando a Helena y se niega a dejarla hablar (905). Es, precisamente, Hécuba quien pide que se deje hablar a Helena, quien propicia el agón, pidiendo que a ella también se le deje hablar (905-908). La esperanza de Hécuba es aquí, cuando menos, paradójica, pues piensa que dándole a conocer a Menelao los males que Helena ha causado a Troya, quedará finalmente sellada su muerte (909-910). ¿Por qué estaría Menelao interesado en los males de Troya? No es claro. La visión de Hécuba es, quizá, ingenua: Menelao ha llegado a vengar los males cometidos contra él y contra los griegos y no cambia de opinión en el resto de la obra.

b) El agón es iniciado por Helena (914-965) $)^{9}$. En este desarrolla una serie de argumentos, algunos más o menos sorprendentes. Culpa de lo sucedido a ella a Hécuba, por haber dado a luz a Paris, así como al anciano por no haber matado al niño (seguro también en referencia Alejandro, la tragedia que el público todavía tenía en mente). Culpa a los dioses, incluso al mismo Menelao. Sólo después de un rato empieza a reconocer que puede haber alguna causa contra ella (945), al no haber dejado Troya una vez Paris había muerto.

9 Este ha sido muchas veces comparado con el Encomio a Helena de Gorgias; incluso se ha hablado de una influencia de este en Eurípides para la construcción de este discurso. Pero, como también lo indica Kovacs (2018), la datación de la obra de Gorgias no es clara, y, por lo demás, son discursos verdaderamente distintos. El defensor de Helena en el Encomio afirma: "En efecto, ya sea por designios de la fortuna y por decisiones de los dioses como por decreto de la necesidad hizo lo que hizo, o raptada por la fuerza, o persuadida por las palabras, o arrebatada por el amor" (6.31). Nuestra Helena, por el contrario, se defiende negando categóricamente que haya sido persuadida $o$ arrebatada por el amor. Su defensa se concentra, precisamente, en la constricción de su voluntad o de su cuerpo. 
Pero aquí ya los culpables, según ella, son los Troyanos y su tercer marido, que la mantuvieron cautiva. Muchos de los argumentos expuestos no corresponden con ninguna tradición mítica $y$, de hecho, pueden parecer cínicos al espectador, pues, según sus propias palabras, Helena llevaba más de diez años sin hacer nada malo por voluntad propia, a pesar de todos los estragos causados a su alrededor. En este tipo de monólogos, que hacen parte del agón, sí que son posibles las palabras poco sinceras del personaje.

La intervención de Hécuba (9691032) pretende responder punto por punto a estos argumentos. Exculpa a las diosas, culpa a Helena de haber caído rendida ante la belleza de Paris, pero, además, de ser ambiciosa y querer el oro de Troya. Le pregunta por qué no opuso ninguna resistencia en Esparta, le dice que no sólo no intentó huir de Troya a la muerte de Paris, sino que desoyó a la misma Hécuba cuando se lo pidió. Sus palabras suenan más sinceras que las de Helena, quizá porque la perspectiva del espectador es de simpatía por Hécuba. Lo que no es claro es que tengan el efecto esperado de asegurar la muerte de Helena.

c) Al final de agón Menelao reconoce estar de acuerdo con Hécuba en que Helena ha ido a Troya voluntariamente y confirma su sentencia de muerte (1036-1040). Pero no dice que haya sido convencido por Hécuba, de hecho, esta parece haber sido siempre la opinión de Menelao. Si no, no hubiera ido por Helena con la intención de matarla por sus culpas. Aquí, entonces, el efecto de las palabras de Hécuba parece haber sido nulo y el tiempo perdido. Acto seguido, ambas mujeres suplican, Helena por su vida, Hécuba por la muerte de Helena (1042-1045). Hécuba, incluso, cambia la argumentación y le pide a Menelao no traicionar a su gente perdonando a Helena. La escena es triste (1046-1051), son dos mujeres llorando desesperadas. Para ambas el momento es decisivo: Helena ve pronta su ejecución, Hécuba parece que pone aquí las únicas esperanzas de justicia. La muerte de Helena sería, de hecho, el único consuelo de Hécuba en esta obra. Menelao afirma que se sostiene en su decisión, pero Eurípides deja sembrada la duda sobre el destino de $\mathrm{He}$ lena, al poner esta duda en boca de Hécuba, que, no convencida de que se ejecutará la sentencia contra Helena, le pide a Menelao que no vaya Helena en el mismo barco que él. Ante la sarcástica pregunta de Menelao de si es que Helena "pesa más ahora” (1050), la respuesta de Hécuba es, de nuevo, una razón para dudar de si el destino de Helena será fatal, pues responde: "una vez amante, siempre amante" $(1051)^{10}$. Al finalizar,

10 Tomo esta traducción de Morwood (Hall y Morwood, 2000), quien a su vez la toma de S.A. BARLOW. 
Menelao, que en ningún momento ha mencionado ni mostrado interés por los desastres ocasionados por Helena en Troya, accede a ir en otro barco y reafirma su sentencia de muerte (1052-1059). Pero afirma que esta será un escarmiento, para que todas las mujeres "sientan temor por su ligereza" (1058-1059). El tono misógino de estas conclusiones no deja duda de que Menelao no matará a Helena (si es que lo hace) por justicia alguna frente al pueblo troyano, lo que muestra, una vez más, que, en realidad, el discurso de Hécuba no ha tenido efecto alguno. La sentencia sería ejecutada para vengar el honor del marido traicionado.

Ha sido ya muy discutido si Eurípides le da, en la sentencia a Helena, alguna justicia al padecimiento de Hécuba. No es claro si realmente se castigará a Helena, debido a que, con todas estas señales de duda de Hécuba, Eurípides podría estar indicando que el destino de Helena será feliz, tal y como lo transmite la tradición. De hecho, queda en el espectador la duda, sembrada por la propia Hécuba, que ve en Helena una seductora a la que nadie se puede resistir. Pero, como indica LLOYD (1984), en realidad Eurípides nunca pone en palabras de Menelao el perdón a Helena, ni siquiera la duda sobre la sentencia. Sabe entonces el trágico ponernos a dudar sobre esta última parte. A la Hécuba de la obra sólo le queda la duda y la promesa de Menelao, pues todo lo demás está fuera de la obra. Siguiendo con LLOYD:

Eurípides podría haber mostrado fácilmente a Menelao perdonando a Helena allí mismo, bien porque le convencieron sus argumentos o porque, estando de acuerdo con Hécuba, admitió que la justicia no significaba nada para él [...] El hecho de que la obra no haga esto, muestra que el escape de Helena, correcto o no, no es un problema de esta obra (1984: 304) ${ }^{11}$.

Así entonces, el debate sobre si hay justicia para Hécuba en la muerte de Helena supera los hechos de la obra y en esta no queda más que la duda. Queda también la duda sobre ¿por qué es Helena la que debe morir? ¿Por qué se concentra toda la culpa en ella? Es paradójico que Hécuba recurra a Menelao para pedir justicia por los actos de una mujer que no combatió, ni mató, y está en la misma playa esperando conocer su suerte. ¿Por qué no quiere vengarse de Menelao, que al final de cuentas sí tomo parte en la batalla y ahora en el saqueo? El pensamiento heroico y la lógica de guerra parecen justificar el comportamiento de los héroes; las mujeres no parecen esperar que los hombres se comporten de forma distinta. Hay un derecho del vencedor a poseer todo lo que le pertenece al vencido, incluyendo a sus mujeres. En este caso, en medio de la profunda humanidad de este dolor, Eurípides parece recordarnos que las troyanas son botín de guerra, sin derecho a réplica. Ellas lloran su

11 La traducción es propia. 
tragedia, pero Casandra es la única que denigra abiertamente de los héroes griegos y que promete vengarse de todo lo que estos han hecho. Y Casandra no habla desde la cordura, las mujeres cuerdas de esta obra no se concentran en las culpas de la guerra. Hay, eso sí, un reclamo en Andrómaca por la muerte de su hijo. Esta, en uno de los momentos más dramáticos y patéticos de la obra, dice: “ $\mathrm{OH}$ griegos, generados de terribles males, dignos de bárbaros! ¿Por qué matan a este niño que de nada es culpable?" (159-760). Mientras, sobre Helena, mujer infiel, se espera que caiga todo el peso de la justicia humana. Al final, esta es totalmente una tragedia femenina.

Para las troyanas no parece haber posible justicia ni consuelo, no, al menos, en los sucesos que quedan en escena. Las posibilidades de esta justicia están más allá del tiempo de la obra: quedan como parte de la ironía trágica y fortalecen la tragedia, pues el espectador sabe que todas estas mujeres están ancladas a la incertidumbre del aquí y el ahora. De todos modos, la venganza de Casandra es la tragedia de Casandra; y Eurípides, al poner fuera de escena la posible muerte de Helena, única mujer con posibilidades de salvación en la obra, enfatiza el hecho de que esta muerte en nada cambiará los hechos trágicos de esta.

\section{Ediciones y traducciones}

CoRtés Copete, J.M. (trad.) (2006). Claudio Eliano. Historias curiosas. Madrid: Gredos.

García Yebra, V. (ed. y trad.) (1992). Poética de Aristóteles. Madrid: Gredos.

Guzmán Guerra, A. (trad.) (2014). Tucídides. Historia de la guerra del Peloponeso. Madrid: Alianza Editorial.

Kovacs, D. (trad.) (2018). Euripides. Troades. Oxford: Oxford University Press.

Marcos, G. y Davolio, M.C. (trads.) (2011). Gorgias, Encomio a Helena. Buenos Aires: Ediciones Winograd.

Moorwood, J, y Hall, E. (ed. y trad.) (2000). Euripides. The Trojan Women and Other Plays. Oxford: Oxford University Press.

Paley, F. A. (ed.) (2010 [11857]). Euripides. Volume I. Cambridge: Cambridge University Press.

Ross, D. (ed.) (1958). Aristotelis. Politica. London: Oxford University Press.

Shapiro, A. y Burian, P. (ed. y trad.) (2009). Euripides. Trojan Women. Oxford: Oxford University Press.

\section{Bibliografía citada}

Croally, N.T. (1994). Euripidean Polemic. The Trojan Women and the function of tragedy. Cambridge: Cambridge University Press.

García Gual, C. (2016). La muerte de los héroes. Madrid: Turner.

García Gual, C. (2020). La deriva de los héroes en la literatura griega. Madrid: Siruela

Gilmartin, K. (1970). "Talthybius in the Troian Women": American Journal of Philology 91/2; 213-222. 
Lloyd, M. (1984). "The Helen Scene in Euripides' Troades": The Classical Quarterly 34/ 2; 303-313.

Murray, G. (1962). Grecia clásica y mundo moderno (trad. de J.M. Gimeno). Madrid: Editorial Norte y Sur.

Recibido: 12-09-2021

Evaluado: 21-09-2021

Aceptado: 23-09-2021 